\title{
Clearance of debris from the iris through the drainage angle of the rabbit's eye
}

\author{
IAN GRIERSON ${ }^{1}$ AND IAN A. CHISHOLM ${ }^{2}$ \\ From the ${ }^{1}$ Institute of Ophthalmology, London, and the ${ }^{2}$ Department of Ophthalmology, University of \\ Saskatchewan, Canada
}

SUMMARY The fate of particulate material on entering the drainage angle of the rabbit's eye was investigated by transmission electron microscopy. The infiltrate was produced by photocoagulation of the iris. Initially it consisted of plasma, connective tissue and cellular debris, fibrin, and red blood cells. Later, free melanin granules, polymorphs, macrophages, and iris clump cells were all seen to enter the drainage system. Native meshwork cells were found to be active phagocytes and began to degrade various components of the infiltrate within 2 hours of the formation of the iris lesions. Corneal endothelial cells, the cells which cover the iris pillars, and the adventitial cells of the ciliary body were less active but were also phagocytic.

The mechanisms of disposal of particulate material through the primate drainage system have been studied by several investigators. It has been found that 2 mechanisms are of importance for the clearance of various forms of debris. Materials which can vary in size between horseradish peroxidase and red blood cells reach the endothelium of Schlemm's canal and enter the drainage vessels via transcellular pores (Segawa, 1971; Inomata et al., 1972) through giant vacuoles (Feeney and Wissig, 1966; McRae and Sears, 1970; Tripathi, 1971, 1974; Inomata et al., 1972) and to some extent by micropinosomes (Fine, 1964; Feeney and Wissig, 1966). If there is a fairly large particulate insult to the drainage system a second mechanism is evoked, that of phagocytosis by the native meshwork cells. Phagocytic activity by trabecular meshwork cells has been reported in the normal eye in various pathological situations and in experimental studies in which red blood cells (Shabo and Maxwell, 1972), colloidal gold and Indian ink (Rohen and Van der Zyphen, 1968), and bacteria and tapetum rods (Lee, 1971) have been injected into the anterior chamber.

Van der Zyphen (1977) has shown that the meshwork cells in rats have phagocytic properties, but there have been few other reports of phagocytic activity by meshwork cells in non-primates. The present investigation supplements and extends a

Address for reprints: Dr I. Grierson, Department of Pathology, Institute of Ophthalmology, Judd Street, London WC1H 9QS preliminary report on the clearance through the rabbit outflow system of iris debris which was released after photocoagulation of the iris (Chisholm and Grierson, 1977).

In previous experimental studies the investigators studied the fate of a single injection of particulate material and its subsequent disposal (Rohen and Van der Zyphen, 1968; Shabo and Maxwell, 1972). The present study follows the progress of material which is continuously being released over a period of several days and, as such, is more comparable to pathological conditions.

\section{Materials and methods}

Twenty-four young adult Dutch rabbits were used in the present investigation. The animals were anaesthetised with veterinary pentobarbitone to a level at which the corneal reflex was absent. The iris in each animal was first constricted with $2 \%$ pilocarpine eye drops and 12 to 15 burns were made in the right iris of each animal. The photic burns were delivered by the Zeiss Oberkochun photocoagulator with the anterior chamber attachment. An instrument power setting which gave an output of 6 joules per second was chosen, and the duration of each burn was approximately 0.5 second.

The rabbits were killed by intracardiac air embolism under pentobarbitone anaesthesia from 2 hours to 90 days after photocoagulation. Both eyes were then enucleated and bisected into anterior and posterior halves under $3 \%$ glutaraldehyde in 
Fig. 1 A giant vacuole $(G V)$ in the endothelium of a vessel of the aqueous plexus (AP) 4 hours after photocoagulation. The vacuole contains plasma $(\times 7250)$

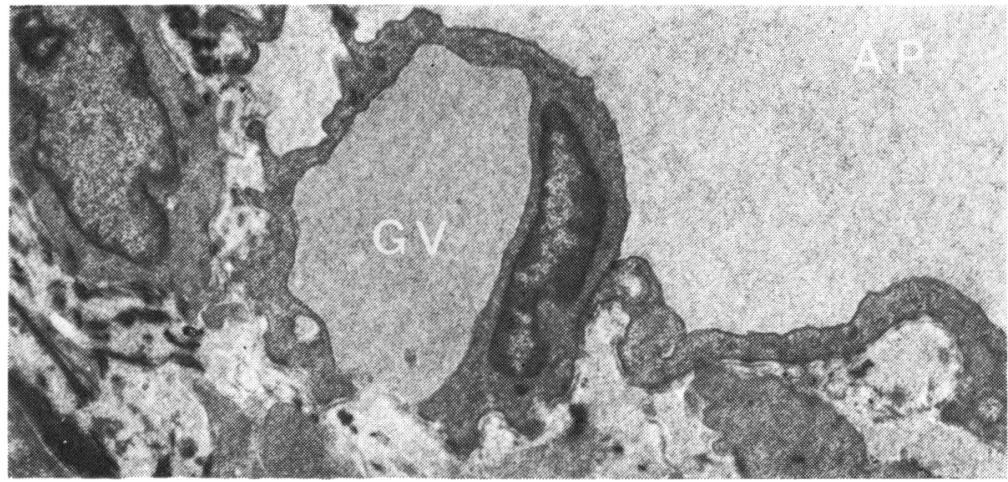

cacodylate buffer. After primary fixation segments of limbal, corneal, and iridic tissues were removed and processed for electron microscopic examination.

Intraocular pressures were measured with a Draeger hand-held applanation tonometer before photocoagulation and then again before the eyes were enucleated. At no time after photocoagulation was intraocular pressure more than $3 \mathrm{mmHg}$ higher in the test than in the corresponding control eye.

\section{Results}

\section{LESIONS IN THE IRIS}

The initial lesions appeared as discrete brown discolourations of the anterior surface of the iris. Thereafter the lesions began to enlarge, and blood, melanin, and other debris were present in the anterior chamber. At 10 days 1 or 2 of the burns had become through-and-through holes. By 90 days there was extensive necrosis of the iris, and much of the posterior surface was depigmented.

\section{DRAINAGE ANGLE}

Control tissue

The drainage angle of the control eyes conformed to the description outline by Tripathi (1974) for the normal rabbit outflow system. The angular region of the rabbit eye is distinguished by having a poorly developed ciliary muscle, a posterior extension of the anterior chamber angle called the ciliary cleft, and a plexus of aqueous collecting vessels called the angular aqueous plexus which corresponds to Schlemm's canal.

\section{2 to 4 hours after photocoagulation}

At 2 hours plasma filled the angle and most of the meshwork, but was not within the vessels of the acqueous plexus. There were a few red blood cells within the drainage tissues, and even at this early stage meshwork cells were engaged in the phacocytosis of red blood cells and plasma.

By 4 hours the infiltrate into the angular tissues was more complex and consisted of plasma, fibrin, disrupted cells, connective tissue debris, many red

Table 1 The various phagocytic cells in the angular region, their diet, and their relative affinities for the various materials are indicated by these symbols: + present,++ common, +++ abundant. The time period indicates when phagocytosis by the particular cell type was first identified

\begin{tabular}{|c|c|c|c|c|c|c|}
\hline & $\begin{array}{l}\text { Hystiocytic } \\
\text { macrophages }\end{array}$ & $\begin{array}{l}\text { Trabecular } \\
\text { meshwork cells }\end{array}$ & Polymorphs & $\begin{array}{l}\text { Adventitial cells } \\
\text { of the ciliary body }\end{array}$ & $\begin{array}{l}\text { Corneal } \\
\text { endothelial cells }\end{array}$ & $\begin{array}{l}\text { Cells which cover } \\
\text { the iris pillars }\end{array}$ \\
\hline Red blood cells & +++ & $+t+$ & & $++t$ & & \\
\hline Polymorphs & +++ & $+\dot{T}$ & & & $\therefore$ & \\
\hline Melanin granules & $+t+$ & $+t+$ & ++ & $+t$ & $+t$ & + \\
\hline Collagen debris & $+t+$ & $t+t$ & $?$ & ++ & & \\
\hline Fibrin & +++ & +++ & $+t+$ & ++ & & \\
\hline Plasma & $\begin{array}{l}+t \\
\text { (4 hours) }\end{array}$ & $\begin{array}{l}t+t \\
\text { (2 hours) }\end{array}$ & $\begin{array}{l}+++ \\
\text { (1 day) }\end{array}$ & $\begin{array}{l}+t \\
\text { (2 days) }\end{array}$ & ( 2 days) & (7 days) \\
\hline
\end{tabular}




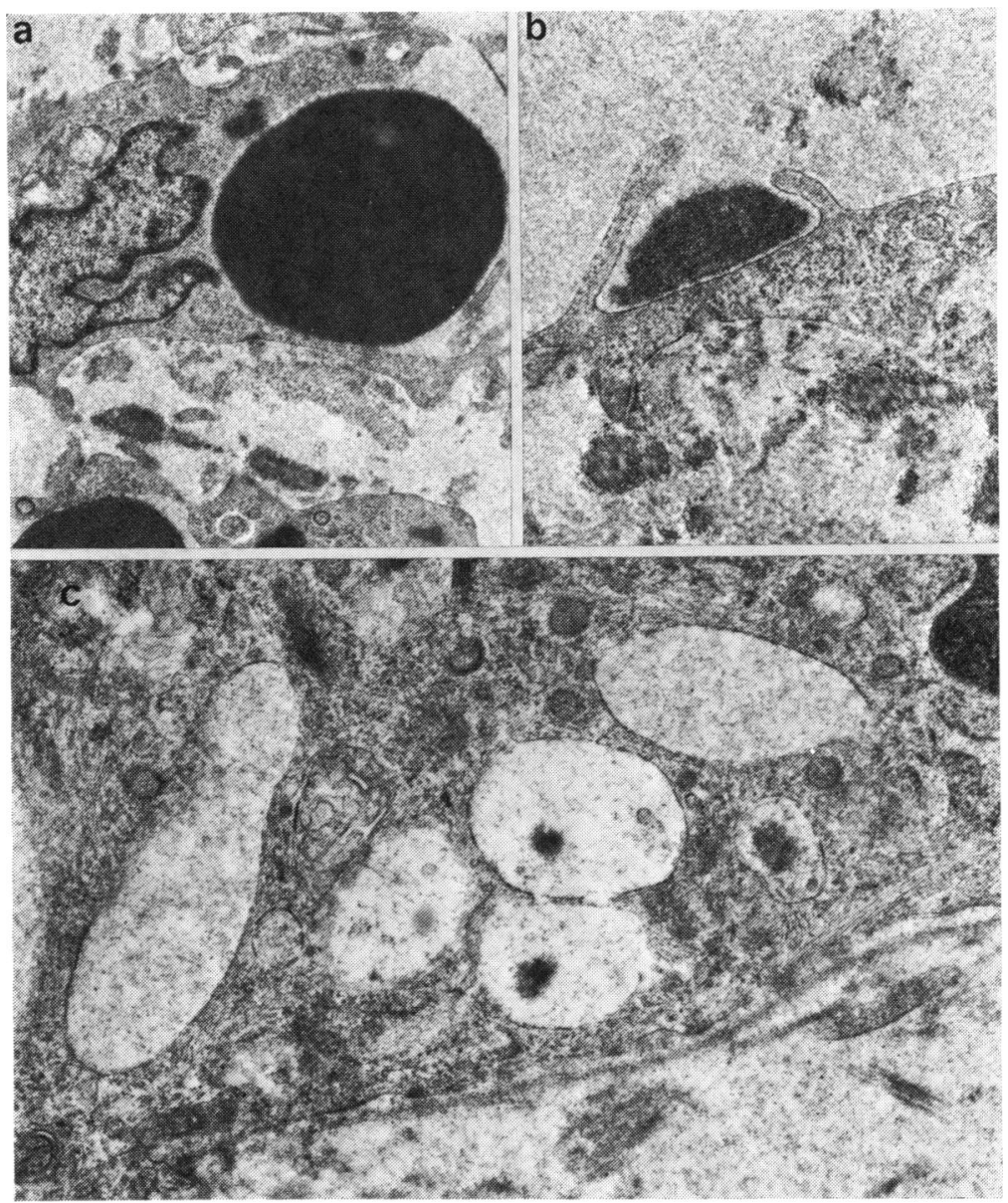

Fig. 2 Meshwork cells in the outflow system 4 hours after photocoagulation. (a) A meshwork cell surrounding a red blood cell. (b) A clump of fibrin which is being enveloped by pseudopodia. (c) Vacuoles which contain plasma and fibrin within a meshwork cell (a $\times 4200$; b $\times 17000$; c $\times 25000$ )

Table 2 The various materials which entered the outflow system and their relative abundance at the appropriate time periods are indicated by these symbols: + present,++ common, +++ abundant

\begin{tabular}{|c|c|c|c|c|c|c|c|}
\hline & Plasma & $R B C S$ & Collagen debris & Fibrin & Polymorphs & Melanin & Large iris cells \\
\hline 2 hours & $+t$ & + & + & & & & \\
\hline 4 hours & $++t$ & $++t$ & $+t$ & ++ & & & \\
\hline 1 day & +++ & +4 & $+t+$ & $+t+$ & $+t$ & ++ & \\
\hline 2 days & $4++$ & $+t$ & $+t+$ & $t+t$ & $++t$ & $-1+t$ & \\
\hline 4 days & $+?$ & + & ++ & & $y++$ & $++t$ & \\
\hline 7 days & & + & $+?$ & & + & $t+$ & + \\
\hline 10 days & & + & & & $+?$ & + & $t+$ \\
\hline 14 days & & + & & & & + & $+1+$ \\
\hline 18 days & & + & & & & & $+t+$ \\
\hline 30 days & & + & & & & & $+1+$ \\
\hline 90 days & & & & & & & + \\
\hline
\end{tabular}


Fig. 3 The angular region 2 days after photocoagulation. (a) Corneal endothelial cells close to the ciliary cleft, which contain melanin granules (arrows). (b) Beneath the trabecular meshwork (TM) the ciliary cleft (CC) contains large numbers of polymorphs $(\mathrm{a} \times 1600 ; \mathrm{b}$ $\times 1520)$

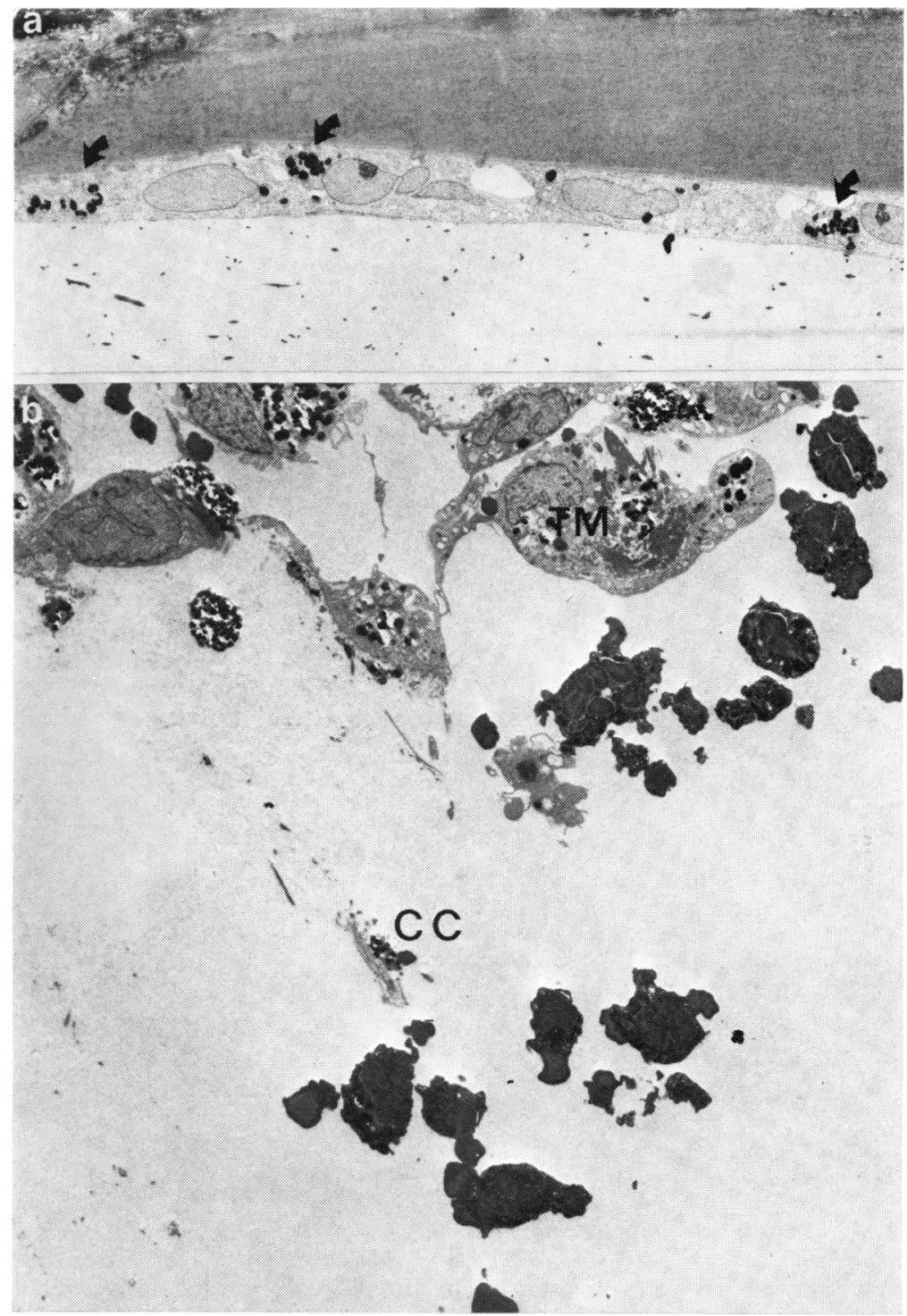

cells, and an occasional macrophage. All the various materials were observed within the giant vacuoles of the endothelium lining the aqueous collecting vessels and had penetrated into the lumina of these vessels (Fig. 1).

Not only did the infiltrate pass through the conventional drainage system but there was lateral passage of the various materials into the ciliary body via the interstitial spaces. Presumably the infiltrate was moving towards the suprachoroid by the socalled uveoscleral drainage route.

In the absence of substantial numbers of macrophages from outside the drainage area the native meshwork cells were the predominant phagocytes in the tissue (Fig. 2 and Table 1).

1 to 4 days after photocoagulation

On day 1 the infiltrate contained 2 additional components, polymorphonuclear leucocytes and melanin granules (Table 2). Many more meshwork cells were now involved in phagocytosis, but they were no longer exclusively phagocytes. Large numbers of histiocytic macrophages were present within the drainage system. The histiocytic macrophages were engulfing a similar range of materials to that taken by the native meshwork cells. The polymorphs 


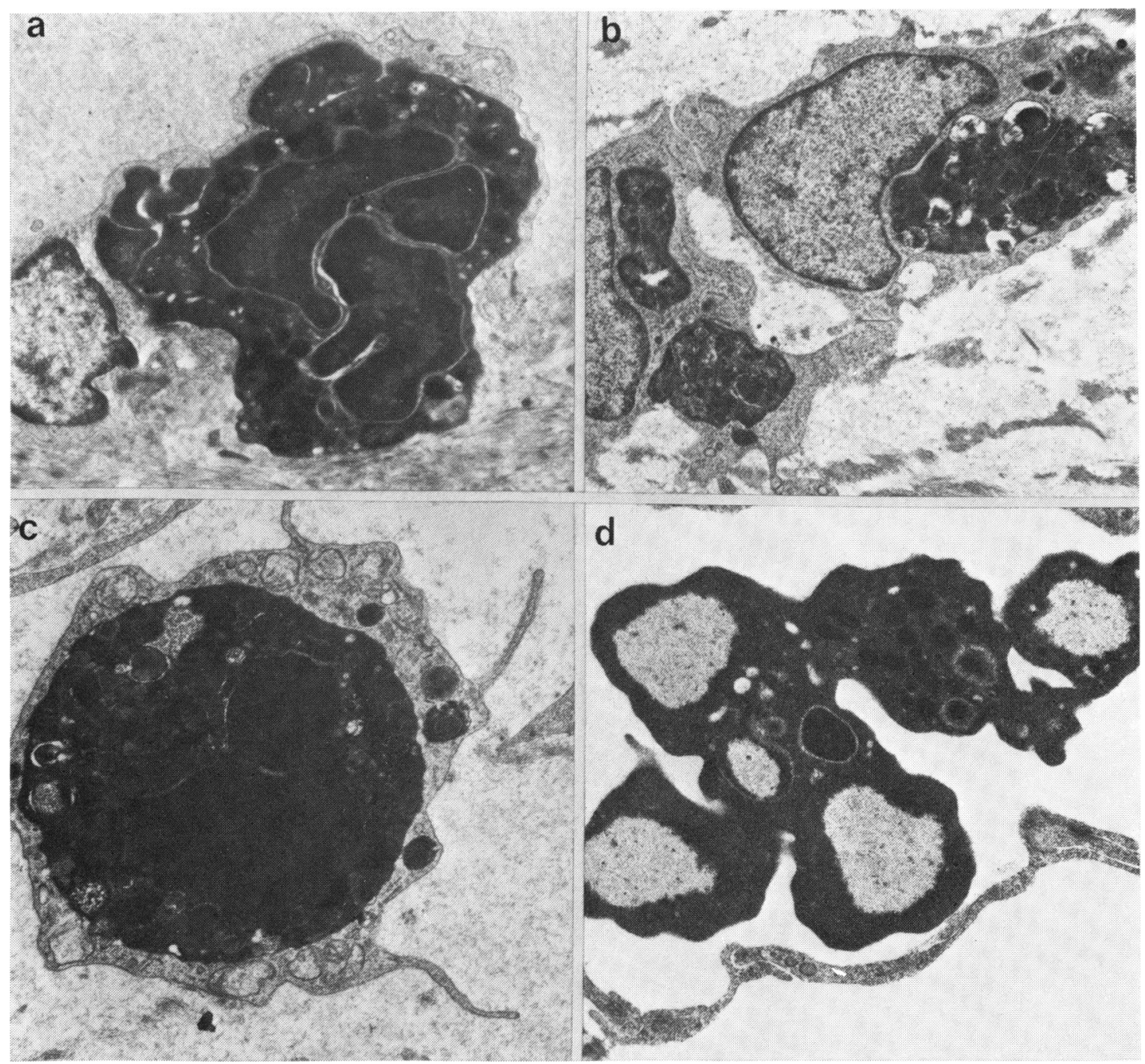

Fig. 4 Polymorphs within the outflow system. (a) A polymorph partially within the lumen of a giant vacuole 2 days after photocoagulation. (b) Polymorph debris within a meshwork cell 4 days after photocoagulation. (c) $A$ fragment of a polymorph which is contained within a macrophage 2 days after photocoagulation. (d) A degenerate polymorph 4 days after photocoagulation $(\mathrm{a} \times 7500 ; \mathrm{b} \times 11700 ; \mathrm{c} \times 12500 ; \mathrm{d} \times 13300)$

were also active phagocytes, but their diet was restricted to fibrin and plasma.

On day 2 the corneal endothelial cells began to incorporate melanin granules (Fig. 3) and the ciliary adventitial cells had started to ingest plasma, fibrin, and other debris (Table 1). Polymorphs had become more frequent; some were engulfing melanin while others were beginning to degenerate. The more vigorous phagocytic cells had in turn begun to ingest the degenerating polymorphs (Fig. 4).

By the second day some of the meshwork cells had become 'activated', which was a process whereby a meshwork cell became detached from the connective tissue of a trabecula and lost its normal association with neighbouring meshwork cells to become fully mobile. The activated meshwork cell was called an endothelial macrophage to distinguish it from the histiocytic or non-native macrophage.

Though it was often difficult to distinguish between endothelial and histiocytic macrophages the former usually had darker cytoplasm and more rough endoplasmic reticulum, and their nuclei were often heavily infolded. The most obvious difference was that histiocytic macrophages had many filopodia or 

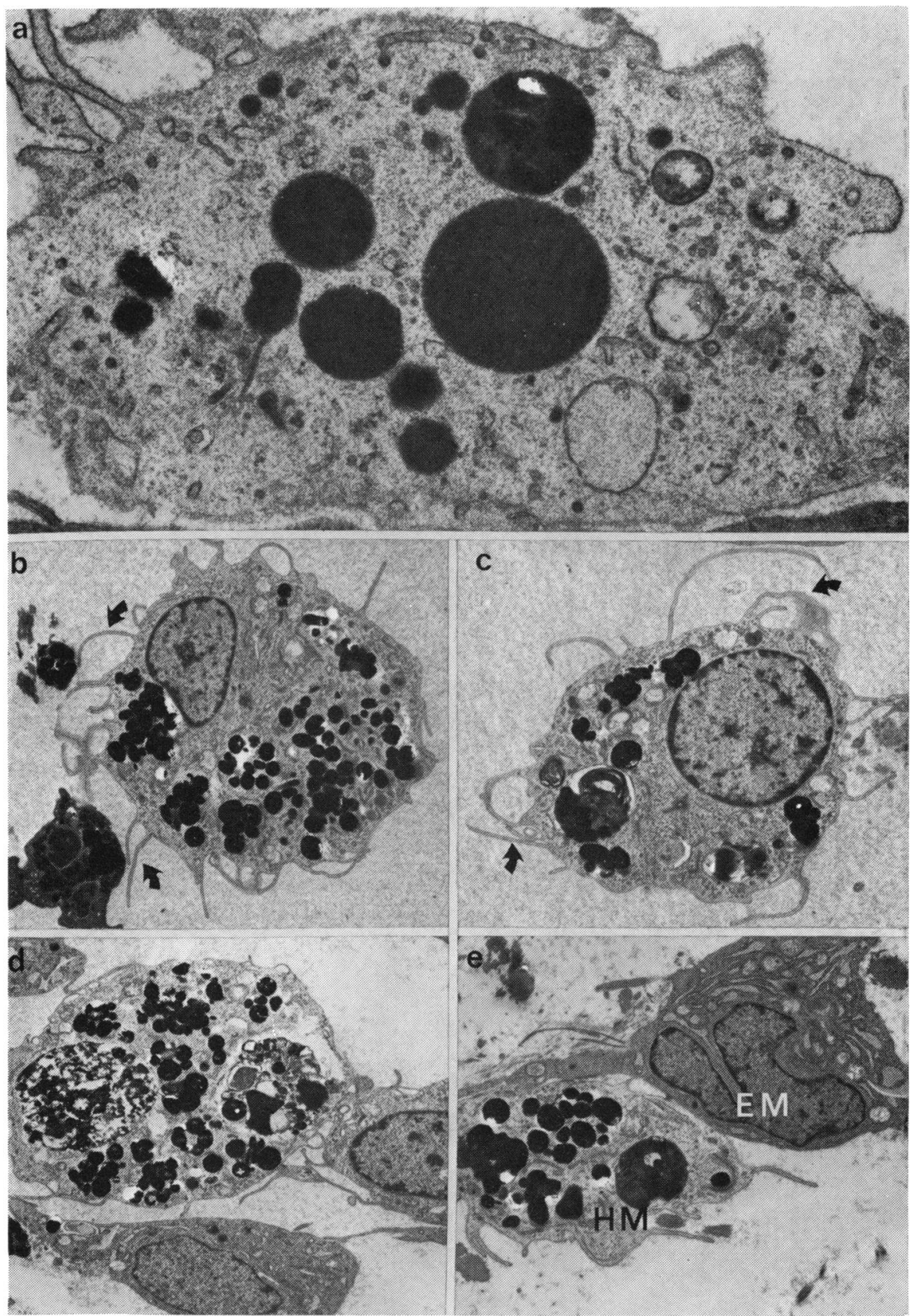

Fig. 5 Histiocytic macrophages within the outflow system 2 days after photocoagulation.

(a) A histiocytic macrophage which contains fragments of haematogenous material. (b) and (c) Histiocytic macrophages with prominent filopodia (arrows) which have ingested melanin granules. (d) A pale staining histiocytic macrophage which contains large secondary lysosomal complexes. (e) A histiocytic macrophage (HM) can be compared with an endothelial macrophage $(E M)(\mathrm{a} \times 16800 ; \mathrm{b} \times 2800 ; \mathrm{c} \times 2800 ; \mathrm{d} \times 3000 ; \mathrm{e} \times 3850)$ 

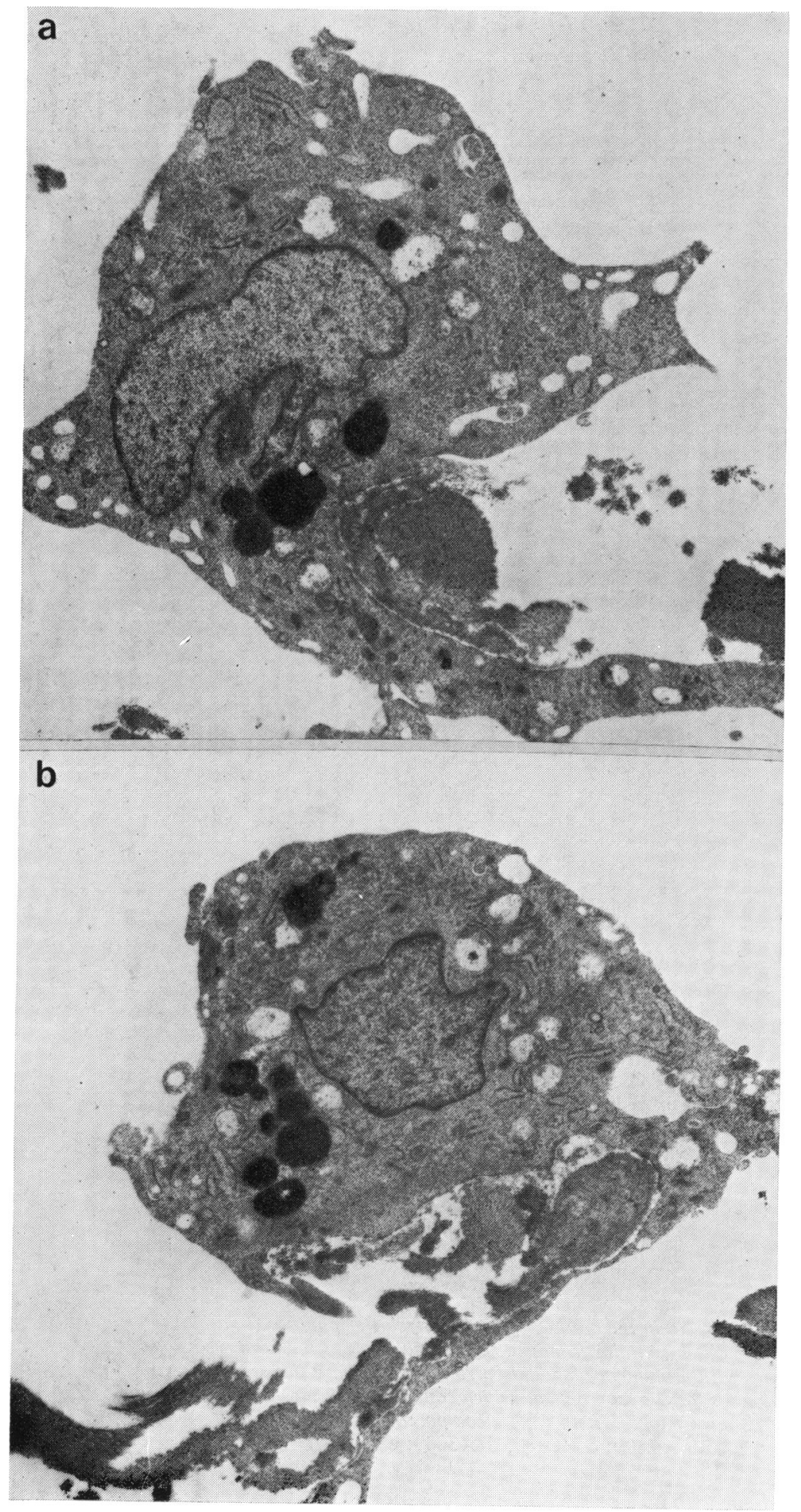

Fig. 6 Meshwork cells in the process of detachment and 'activation' 7 days after photocoagulation. In both (a) and (b) the cells appear to be becoming detached and free moving $(\times 10300)$ 
Fig. 7 A meshwork cell 7 days after photocoagulation. The cell is no longer associated with other meshwork cells and is therefore considered to be 'free' and 'activated'. The meshwork cell contains numerous large electronlucent vesicles, which indicates that this macrophage has been heavily committed to the degradation of plasma and fibrin $(\times 8600)$
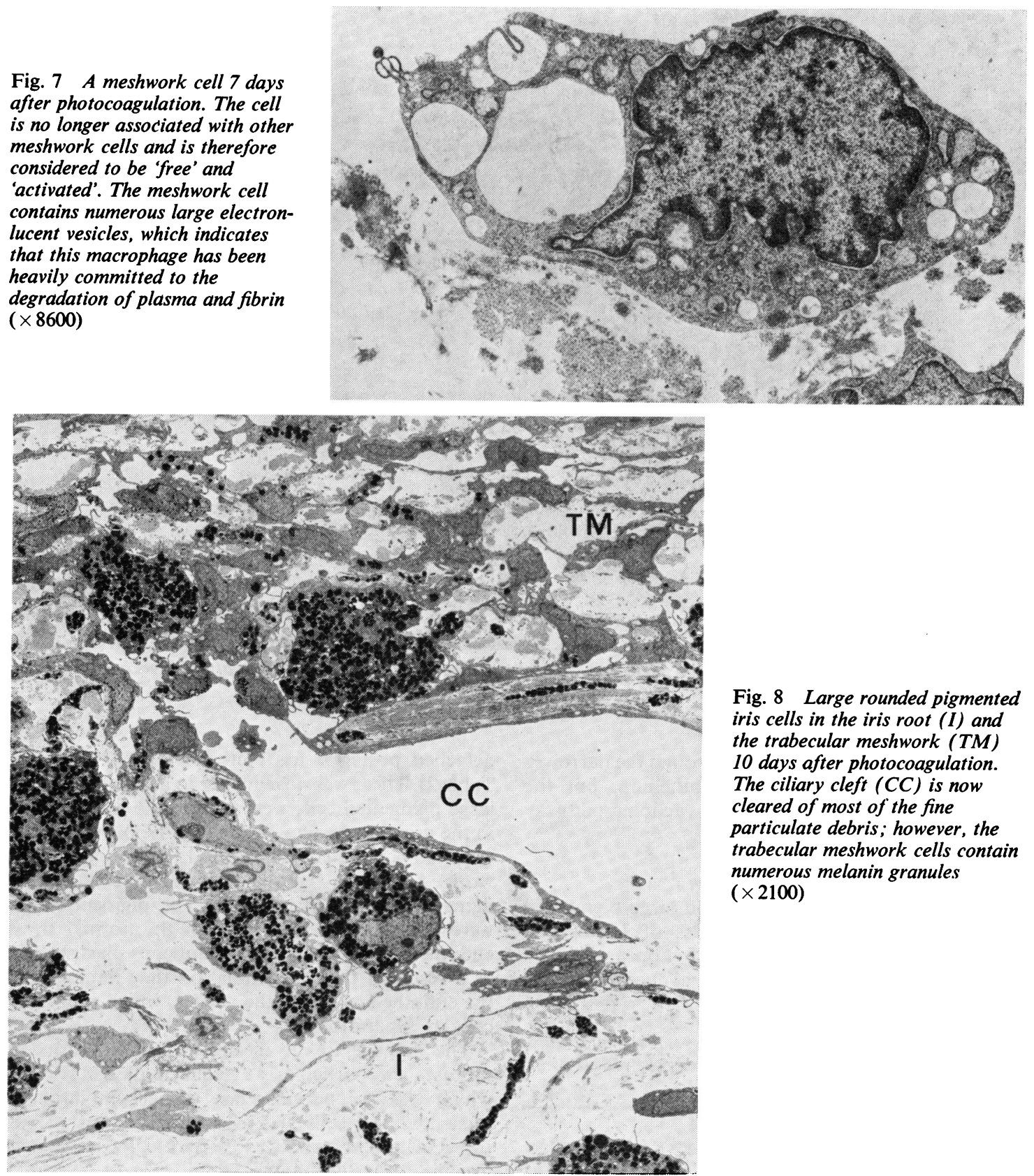

Fig. 8 Large rounded pigmented iris cells in the iris root (I) and the trabecular meshwork (TM) 10 days after photocoagulation. The ciliary cleft (CC) is now cleared of most of the fine particulate debris; however, the trabecular meshwork cells contain numerous melanin granules $(\times 2100)$

cytoplasmic processes which projected from the cell surface, whereas the endothelial macrophages and trabecular meshwork cells did not have these structures (Figs. $4 c, 5,6$, and 7). Four days after photocoagulation the polymorphs were extremely degenerate and had pyknotic nuclei, patchy areas of cytoplasmic lucency, and bizarre outlines (Fig. 4d). These cells were rapidly being lost from the system either through the drainage channels or by vigorous phagocytosis (Fig. 4). The route taken by red blood cells, polymorphs, histiocytic macrophages, and endothelial macrophages into the aqueous plexuses 


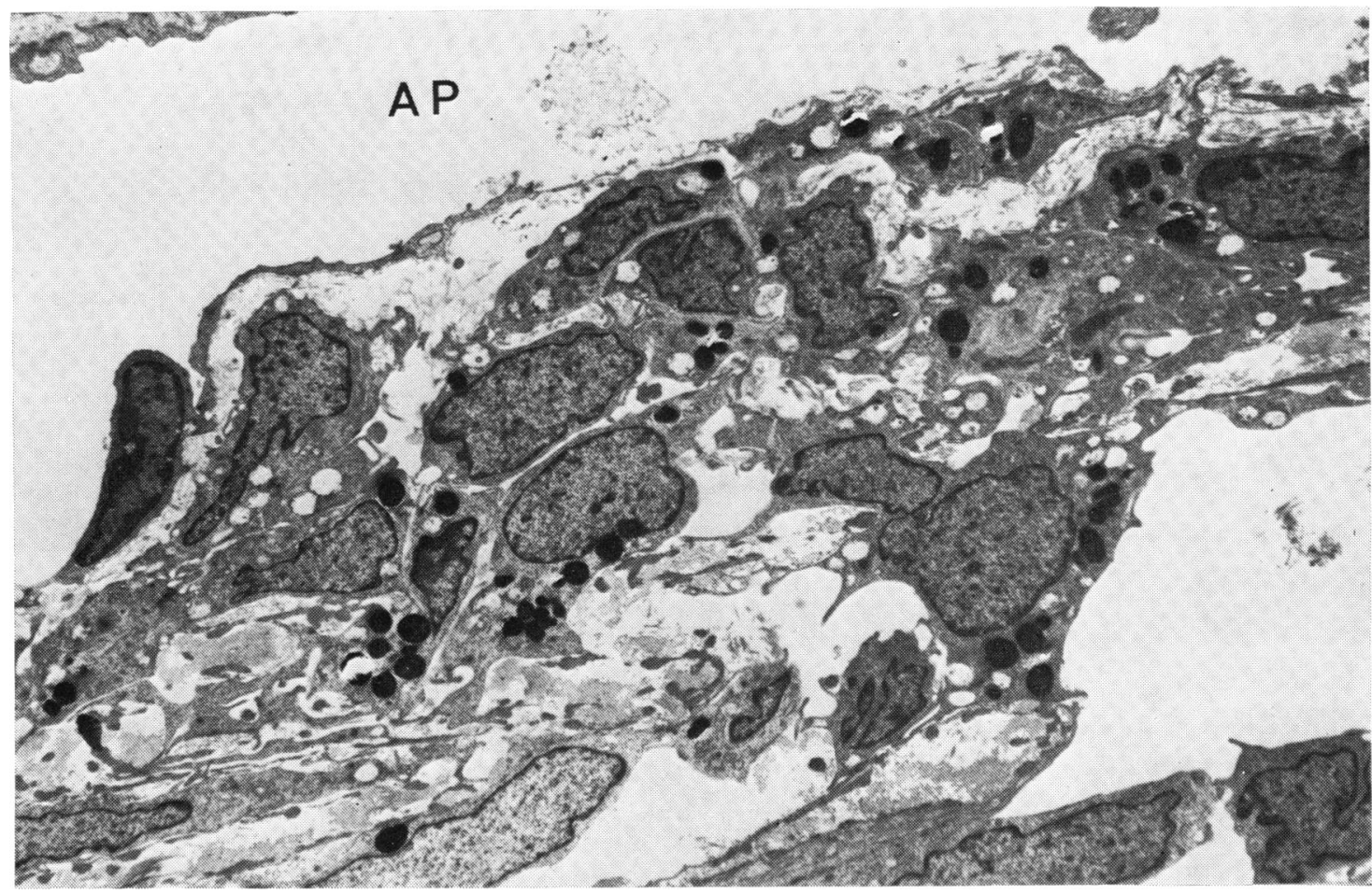

Fig. 9 The trabecular tissues close to a vessel of the angular aqueous plexus (AP) 30 days after photocoagulation of the iris. The endothelium which limits the vessel is discontinuous (arrows) $(\times 5000)$

was either via giant vacuoles or through the narrower attenuated portions of the endothelium, but the particulate debris used only the vacuolar pathway (Table 3).

\section{7 to 90 days after photocoagulation}

Seven days after photocoagulation large pigmented iris cells with diameters in excess of $15 \mu \mathrm{m}$ had arrived in the drainage system. It appeared likely that they were mobilised iris stromal clump cells and

Table 3 The exit route for the passage of the infiltrate through the endothelium which surrounds the vessels of the aqueous plexus

\begin{tabular}{ll}
\hline $\begin{array}{l}\text { Exit route into the vessels } \\
\text { of the aqueous plexus }\end{array}$ & Particulate materials in outflow system \\
\hline Giant vacuoles & $\begin{array}{c}\text { Plasma, fibrin, connective tissue debris, } \\
\text { cellular debris, and free melanin } \\
\text { granules }\end{array}$ \\
$\begin{array}{c}\text { Giant vacuoles and } \\
\text { transcellular channels }\end{array}$ & $\begin{array}{c}\text { Red blood cells, polymorphonuclear } \\
\text { leucocytes, histiocytic macrophages, } \\
\text { and endothelial macrophages }\end{array}$ \\
$\begin{array}{c}\text { Ruptures in the vessel } \\
\text { endothelial monolayer }\end{array}$ & Large pigmented iris cells \\
\hline
\end{tabular}

detached posterior iris epithelial cells (Fig. 8 and Table 2). There was no evidence to indicate that these large pigmented cells were phagocytic when present in the drainage system. By day 18 the pigmented iris cells had penetrated deeply into the trabecular meshwork and had caused considerable structural damage during their passage. The pigmented cells were too large to pass through the normal transendothelial pore system of the aqueous plexuses, and as a result of their accumulation they impinged on the endothelium lining the vessels, which resulted in cellular separation.

The damage to the meshwork and the aqueous plexuses was particularly evident on day 30 (Fig. 9), which was the period when the accumulation of pigmented iris cells was greatest. At this stage the trabecular meshwork was extremely loose and disorganised, partly because of the damage caused by the large iris cells and partly because of the activation of so many meshwork cells into mobile endothelial macrophages.

Only a few pigmented iris cells remained 90 days after photocoagulation, and the endothelium of the angular aqueous plexus had re-formed into an intact monolayer. The outflow system had to some extent 
returned to normal except that it was deficient in native meshwork cells.

\section{Discussion}

The fate of particulate material which enters the rabbit drainage system is either (a) to pass through the trabecular meshwork and into the vessels of the angular aqueous plexus, or $(b)$ to move into the ciliary body via the interstitial spaces, or $(c)$ to be engulfed by phagocytic cells.

Giant vacuoles serve as the main route by which aqueous is transferred across the endothelium surrounding the vessels of the angular aqueous plexus (Tripathi, 1974). Therefore the mechanism of fluid passage is similar to that into Schlemm's canal in primates (Holmberg, 1965; Kayes, 1967; Tripathi, 1968, 1971; Inomata et al., 1972; Grierson and Lee, 1974, 1975). In the present investigation we have shown that giant vacuoles not only serve as a drainage pathway for aqueous humour but allow the egress of particulate material and cells from the meshwork into the lumina of the vessels. Mobile flexible cells like macrophages, polymorphs, and even red blood cells have a second option, and that is to pass through a transcellular opening which does not involve the formation of a giant vacuole. The so-called non-vacuolar transcellular channels have been described in the endothelium on the trabecular aspect of Schlemm's canal in the primate (Segawa, 1971; Inomata et al., Smelser, 1972; Grierson and Lee, 1975). Thus the system of vacuolar and nonvacuolar channels can be considered both as a drainage pathway and as a safety mechanism. By allowing the passage of particulate material from the spaces of the endothelial meshwork the dual hazards of abnormal elevation of intraocular pressure and loss of integrity of the endothelial monolayer can be avoided. Seven days after photocoagulation large pigmented iris cells began to enter the outflow system. The large pigmented iris cells could not pass through the transendothelial channels. Thus the safety mechanism was ineffectual, and the endothelial monolayer was disrupted by the build-up of these large cells in the endothelial meshwork. Similar large pigmented iris cells have been described in the outflow system of a patient with pigment dispersion phenomena (Iwamoto et al., 1971).

The phagocytic capability of the native trabecular meshwork cells in the rabbit outflow system appears to be well developed. These cells can engulf and degrade a great variety of material from fibrin and plasma to polymorphs and red blood cells. Phagocytosis can be evoked in a remarkably short time, so that by 2 hours after photocoagulation some meshwork cells had taken in red cells and plasma.
The native meshwork cells are not the only local phagocytes in the drainage angle, since corneal endothelial cells, the cells which cover the iris pillars, and the adventitial cells of the ciliary body also could be stimulated, but only after prolonged exposure to the infiltrate. The phagocytic behaviour of the rabbit trabecular meshwork cells is very similar to that described in the monkey (Rohen and Van der Zyphen, 1967) and in man (Grierson and Lee, 1973). The cells become activated after their phagocytic burden has reached a critical level and lose contact with their neighbours to become wandering histiocytes.

The ability of native meshwork cells to become active phagocytes is of some importance, and malfunction of this phagocytic process has been proposed as a possible contributory factor to the development of primary open-angle glaucoma (Bill, 1975). Certainly in many of the conditions which are classified as secondary open-angle glaucoma such as haemolytic glaucoma (Yamashita and Rosen, 1965), pigmentary glaucoma (Iwamoto et al., 1971), and pseudoexfoliation glaucoma (Ringvold and Vegge, 1971) meshwork cells actively ingest components of the various infiltrates. Therefore it can be assumed that, if the infiltrates are responsible for the pathological elevation of the intraocular pressure, they must invade the drainage tissues in such quantities that neither the vacuolar drainage channels nor the filtering capabilities of the meshwork cells can cope with the influx.

This work was in part supported by the Scottish Hospital Endowments Research Trust (Grant No. 442) and the Clinical Teaching and Research Committee, University of Saskatchewan. The aid is gratefully acknowledged.

We also wish to thank Professor W. S. Foulds and Dr W. R. Lee, of the Tennent Institute of Ophthalmology, Glasgow University, for their help and encouragement. Mrs A. Wood is thanked for her secretarial assistance.

\section{References}

Bill, A. (1975). The drainage of aqueous humour. Investigative Ophthalmology, 14, 1-3.

Chisholm, I., and Grierson, I. (1977). Particulate phagocytosis by trabecular meshwork endothelium. Canadian Journal of Ophthalmology, 12, 293-299.

Feeney, M. L., and Wissig, S. (1966). Outflow studies using an electron dense tracer. Transactions of the American Academy of Ophthalmology and Otolaryngology, 70, 791-798.

Fine, B. S. (1964). Observations on the drainage angle in man and monkey. Investigative Ophthalmology, 3, 609-646. Grierson, I., and Lee, W. R. (1973). Erythrocyte phagocytosis in the human trabecular meshwork. British Journal of Ophthalmology, 57, 400-415.

Grierson, I., and Lee, W. R. (1974). Changes in the monkey outflow apparatus at graded levels of intraocular pressure: 
a qualitative analysis by light microscopy and scanning electron microscopy. Experimental Eye Research, 19, 21-33.

Grierson, I., and Lee, W. R. (1975). Pressure induced changes in the ultrastructure of the endothelium lining Schlemm's canal. American Journal of Ophthalmology, 80, 863-884.

Holmberg, A. S. (1965). Schlemm's canal and the trabecula meshwork. An electron microscopic study of the normal structure in man and monkey (Cercopithecus ethiops). Documenta Ophthalmologica, 19, 339-373.

Inomata, H., Bill, A., and Smelser, G. K. (1972). Aqueous humour pathways through the trabecular meshwork and into Schlemm's canal in the cynomolgus monkey (Macaca irus). An electron microscopic study. American Journal of Ophthalmology, 73, 760-789.

Iwamoto, T., Witmer, R., and Landolt, E. (1971). Light and electron microscopy in absolute glaucoma with pigment dispersion phenomena and contusion angle deformity. American Journal of Ophthalmology, 72, 420-434.

Kayes, J. (1967). Pore structure of inner wall of Schlemm's canal. Investigative Ophthalmology, 6, 381-393.

Lee, W. R. (1971). The study of the passage of particles through the endothelium of the outflow apparatus of the monkey eye by scanning and transmission electron microscopy. Transactions of the Ophthalmological Societies of the United Kingdom, 91, 687-705.

McRae, D., and Sears, M. L. (1970). Peroxidase passage through the outflow channels of human and rhesus eyes. Experimental Eye Research, 10, 15-18.

Ringvold, A., and Vegge, T. (1971). Electron microscopy of the trabecular meshwork in eyes with exfoliation syndrome
(Pseudo-exfoliation of the lens capsule). Virchows Archiv für pathologische Anatomie und Physiologie und für klinische Medizin, 353, 110-127.

Rohen, J., and Zyphen, E. (1968). The phagocytic activity of the trabecular meshwork endothelium. Albrecht von Graefes Archiv für klinische und experimentelle Ophthalmologie, 175, 143-160.

Segawa, K. (1971). Pores of the trabecular wall of Schlemm's canal: Ferritin perfusion in enucleated human eyes. Japanese Journal of Ophthalmology, 15, 1-8.

Shabo, A. L., and Maxwell, D. S. (1972). Observations on the fate of blood in the anterior chamber. A light and electron microscopic study of the monkey tabecular meshwork. American Journal of Ophthalmology, 73, 25-36.

Tripathi, R. C. (1968). Ultrastructure of Schlemm's canal in relation to aqueous outflow. Experimental Eye Research, 7, 335-341.

Tripathi, R. C. (1971). Mechanism of aqueous outflow across the trabecular wall of Schlemm's canal. Experimental Eye Research, 11, 116-121.

Tripathi, R. C. (1974). Comparative physiology and anatomy of the aqueous outflow pathway. In The Eye, vol. 5, pp. 163-356. Edited by H. Davson. Academic Press: London.

Van der Zyphen, E. (1977). Experimental morphological study on structure and function of the filtration angle of the rat eye. Ophthalmologica, 174, 285-298.

Yamashita, T., and Rosen, D. A. (1965). Electron microscopic study of trabecular meshwork in clinical and experimental glaucoma with anterior chamber hemorrhage. American Journal of Ophthalmology, 60, 427-434. 